\title{
Examining the Intergovernmental and Interorganizational Network of Responding to Major Accidents for Improving the Emergency Management System in China
}

\author{
Pan Tang $\mathbb{D}^{1,2}$ Haojia Chen, ${ }^{1}$ and Shiqi Shao ${ }^{1}$ \\ ${ }^{1}$ School of Public Management/Emergency Management, Research Center of Emergency Management, Jinan University, \\ Guangzhou, China \\ ${ }^{2}$ Department of Building and Real Estate, The Hong Kong Polytechnic University, Hong Kong
}

Correspondence should be addressed to Pan Tang; tangpan001@163.com

Received 9 July 2018; Accepted 6 September 2018; Published 1 November 2018

Academic Editor: Pasquale De Meo

Copyright (@ 2018 Pan Tang et al. This is an open access article distributed under the Creative Commons Attribution License, which permits unrestricted use, distribution, and reproduction in any medium, provided the original work is properly cited.

\begin{abstract}
Since the SARS crisis in 2003, institutionalized emergency management systems have been established in each government level for improving inter-organizational collaboration in China. Major accidents require participation of public organizations affiliated with multiple government levels, and the lack of collaboration and coordination among the involved organizations within the critical time constraints during the response process is an existing problem. In this research, a case study of examining the intergovernmental and cross-sectoral collaboration for responding to a well-known oil pipeline explosion accident in China by a complex network method is conducted. The aim is to obtain managerial insights in improving the existing emergency management system in a centralized political-administrative context, such as China. A mixed method of data collection is applied to identify the participating organizations and to determine the interaction spanning organizational boundaries in both hierarchical and horizontal dimensions. An emergency response network is built and visualized for representing intergovernmental and interorganizational collaboration during the response process of the major accident by social network analysis (SNA) tools. The SNA indicators are used to measure quantitatively the network structure at the levels of the whole network, subnetwork, and node. The obstacles of achieving intergovernmental collaboration are found, and managerial suggestions for improving the existing emergency management system are provided. This research indicates that the Chinese government should pay attention to establishing and sustaining partnerships with private and nonprofit organizations and conduct a blend of hierarchical, market, and network principles in fostering collaboration for addressing major accidents. The public organizations in the local government level are shown to be more active than other participators in coordinating their response operations, and their capability should be emphasized for improvement. Additionally, the interactive relationships among specific emergency function groups and between the affected communities and organizations performing emergency command and coordination function should be strengthened.
\end{abstract}

\section{Introduction}

Major accidents always cause serious consequences to cities and overwhelm the capabilities of local governments. When emergency response extends above the local government to the provincial and central governments, public organizations affiliated with multiple government levels, as well as private and nonprofit sectors, are required to collaborate and interact with each other toward addressing the disastrous situation [1-3]. Effective response to major accidents depends on intergovernmental and multiorganizational collaboration and networks $[4,5]$. The dynamic and complex environment of rapidly evolving emergencies requires a different flexible approach than the traditional hierarchical mechanism. Legal authorities, responsibilities, resources, and information involved in responding to major accidents are currently dispersed among sectors affiliated with different governments in China. Such fragmentation makes accomplishing common objectives extremely difficult in emergency management. Lack of collaboration and coordination among the numerous 
participants is an existing barrier that reduces emergency response effectiveness [6].

Interorganizational collaboration and networks for addressing emergencies has become widely accepted in practice [6,7]. Since the SARS crisis in 2003, the Chinese government has been trying to establish an emergency management system [8]. For fulfilling the jurisdictional emergency management responsibility, each level of government designed and sustained an emergency management network consisting of governmental sectors, vertical management sectors, public companies, and institutions for improving collaboration among organizations with formal responsibilities and providing continuous emergency services to communities. Successful response to major accidents comprises rapid participation and collaboration among organizations from institutionalized emergency management networks in multiple government levels. As the accident breaks out, evolving and overwhelming capacities of local governments, governments at the higher levels activate the network once the disaster situations are evaluated to satisfy the specified conditions [9], and an intergovernmental network is formed for adapting to the dynamic situation. However, whether the established emergency management networks at multiple government levels can be induced to converge on the achievement of common objectives is an existing problem. Moreover, the function of each government level, as well as private and nonprofit sectors, should also be examined and explored.

Examining the intergovernmental network responding to major accidents provides an effective way to understand the collaborative process among the diversified participating organizations from system perspectives and helps to identify barriers of achieving successful emergency response collaboration. In addition, that will present implication to improve the existing emergency management system in China and to promote network-wide integration across government levels. During a response to major accidents, multiorganizational collaboration based on interorganizational relationships in both hierarchical and horizontal dimensions is essential toward addressing the disastrous situation [10]. In the hierarchical dimension, particularly in the context of China [11], interorganizational hierarchies specified in the political-administrative structure provide an important way to arrange response operations for facilitating collaboration among participants. Meanwhile, horizontal relationships among public organizations without formal hierarchical arrangement, as well as private and nonprofit sectors, are essential to improve interaction spanning organizational boundaries [6]. Furthermore, an appropriate emergency response network structure is essential for improving interaction among all the participating organizations, such as the development of common understanding of emergency situations and problems to be solved, the commitment to common incident objectives and plans, the extent to which all stakeholders are included in the process, and the recognition and management of interdependence among involved organizations [12-14].

The well-known oil pipeline explosion accident that occurred on November 22nd, 2011, in Qingdao City,
Shandong Province, provides a valuable opportunity to examine the intergovernmental and interorganizational collaboration in responding to special major accidents in the Chinese centralized political-administrative context. The investigation report of the State Council in China reveals that the failure of information sharing and lack of collaboration led to poor situation assessment and decision-making which directly caused disastrous consequences. Building on and contributing to the existing research on interorganizational collaboration and network analysis in emergency management, this research investigates the diversified participating organizations and varying levels of collaborative interaction across organizational boundaries in responding to the aforementioned major accident in China from network perspectives [15]. It aims to examine how public sectors affiliated with multiple government levels, as well as private and nonprofit sectors, interact and work together toward addressing major accidents in the context of the existing emergency management institutional arrangement in China. The following questions are examined and analyzed in China: (1) Which organizations participate in the emergency response process of addressing major accidents? (2) What are the structural characteristics of the emerged intergovernmental emergency response network? (3) What are the obstacles of achieving intergovernmental and cross-sectoral collaboration in this specific field from network structure perspectives? (4) How can the institutionalized emergency management system in China be improved?

The content analysis of multiple data sources was conducted to identify involved organizations and to determine diversified types of collaborative interaction across organizational boundaries in both hierarchical and horizontal dimensions in this empirical case. Social network analysis (SNA) concepts and tools are used to build, visualize, and analyze the complex emergency response network. The network structural properties are analyzed quantitatively using an SNA software tool at the level of the node, subset of nodes, and whole network. The key organizations involved in the response process are identified and discussed. In particular, block analysis is applied to present interactive relationships among groups of organizations with same attributes and shows the barriers of interorganizational collaborative response in the empirical case. Furthermore, the network analysis results are discussed and the possible improvement of the existing emergency management system in China is presented. The rest of this paper is organized as follows. Section 2 introduces the literature review of intergovernmental collaboration and relevant governance mechanisms and the emergency management network. The existing emergency management system of addressing major accidents in China is presented in Section 3 for providing the background of this research. The conceptual framework of intergovernmental and interorganizational networks is presented in Section 4 . Section 5 presents the context of the empirical case, data sources, and research method. In Section 6, the emergency response network of the "11.22" oil pipeline explosion accident is built and visualized, and the network structures are measured and analyzed based on a SNA tool. The characteristics of the network of major accident response are 
discussed and managerial suggestions in providing insight to improve the current emergency management system are provided in Section 7. Finally, Section 8 concludes this research.

\section{Literature Review}

The literature examining intergovernmental collaboration and the emergency management network provides the theoretical basis of this research and is discussed in this section.

\subsection{Intergovernmental Collaboration and Governance. Inter-} governmental collaboration across the governmental sector's boundaries and interorganizational collaboration among public, private, and nonprofit sectors are common in emergency management practice and are essential to achieve effective response to large-scale emergencies [16]. Each involved sector performs specific roles and responsibilities and should collaborate with others toward improving information communication, resource sharing, and action coordination. The mandated and emerging collaboration in addressing emergencies relies on the intergovernmental and cross-sectoral relationships [17]. On the one hand, the existing institutionalized interorganizational hierarchies specified in the political-administrative structure are employed to coordinate multiple organizations to achieve rapid collaboration when responding to major accidents [3]. On the other hand, responding to major accidents requires collaboration and coordination among public organizations without hierarchical relationships, as well as among public, private, and nonprofit sectors.

From the existing literature, addressing emergencies involving intergovernmental and cross-sectoral collaboration uses the combination of all the existing three governance mechanisms, including hierarchical, market, and network governance [3]. The first mechanism is the traditional model and relies on the chain of command, standardized procedures, and supervision. In the market mechanism, the supervision is less and the price is emphasized to sustain collaboration. Finally, the network mechanism reflects the horizontal reciprocal patterns of exchange and interrelationships among entities. The combination of multiple governance mechanisms necessitates the creation of a dynamic mixture governance mode to improve collaboration in emergency management.

\subsection{Emergency Management Network. The widely existing} intergovernmental and cross-sectoral collaboration forms the interorganizational network in the field of emergency management. The network provides an effective tool to define and understand the interdependence and varying levels of iteration among public organizations affiliated with multiple government levels, as well as private and nonprofit sectors [18]. The latest literature indicates that collaborative processes and structures work closely together in fostering effective interorganizational collaboration and determine the collaborative outcomes $[19,20]$. In particular, the collaborative process among organizations and their relationships interacts with and is shaped by network structure arrangements. Therefore, appropriate emergency response network structures are a necessary condition for facilitating successful interorganizational collaboration. In recent years, there has been rapid growing research on emergency management networks [21]. In particular, the empirical network research in emergency management using SNA as its methods is an emerging trend $[11,12,22]$. SNA refers to a range of methods of visualizing and analyzing interaction among nodes and provides tools to examine structural and relational patterns of social system and processes [11]. The existing research on emergency management networks concentrates on examining interorganizational collaborative processes at the node level, subset node level, and whole network level.

Despise rapid growth in network research in emergency management, theory construction, methodological rigor, and conceptual clarity are lacking. Second, the existing literature in this field is mainly on conducting research on interaction and collaboration among participating organizations in the western political-administrative context. The centralized political-administrative structure in China impacts the intergovernmental and multiorganizational collaboration deeply, which is different from the empirical emergency management network in most of the existing literature [11]. The existing research gap motivates us to examine the intergovernmental and multiorganizational collaboration in addressing special major accidents which involves all government levels in the institutionalized Chinese emergency management system.

\section{Background of the Chinese Emergency Management System}

This section introduces the existing emergency management system in China. It provides the institutional design for addressing major accidents, which is a typical interorganizational collaborative arrangement across multiple government levels.

After the SARS crisis in 2003, the Chinese government began to establish comprehensive emergency management systems for addressing both natural and man-made emergencies. For fulfilling the jurisdictional management responsibilities of addressing emergencies, each government established an emergency management network consisting of government sectors, departments of party committee, state-owned enterprises, and public institutions to improve collaboration among the participants in a jurisdictional area according to the Act on Addressing Emergencies of the People's Republic of China [23]. The specific emergency management responsibilities and roles of each participating organization are specified. First, an emergency management office (EMO) is set up at each government level to coordinate and manage the network activities of all the involved sectors as a network administrative organization [24]. An emergency management committee consisting of representatives from the main member organizations is established to address strategic-level problems, thereby leaving the daily operations to EMO. Second, each government sets up specific emergency command headquarters for coordinating involved organizations to address particular emergencies with higher 


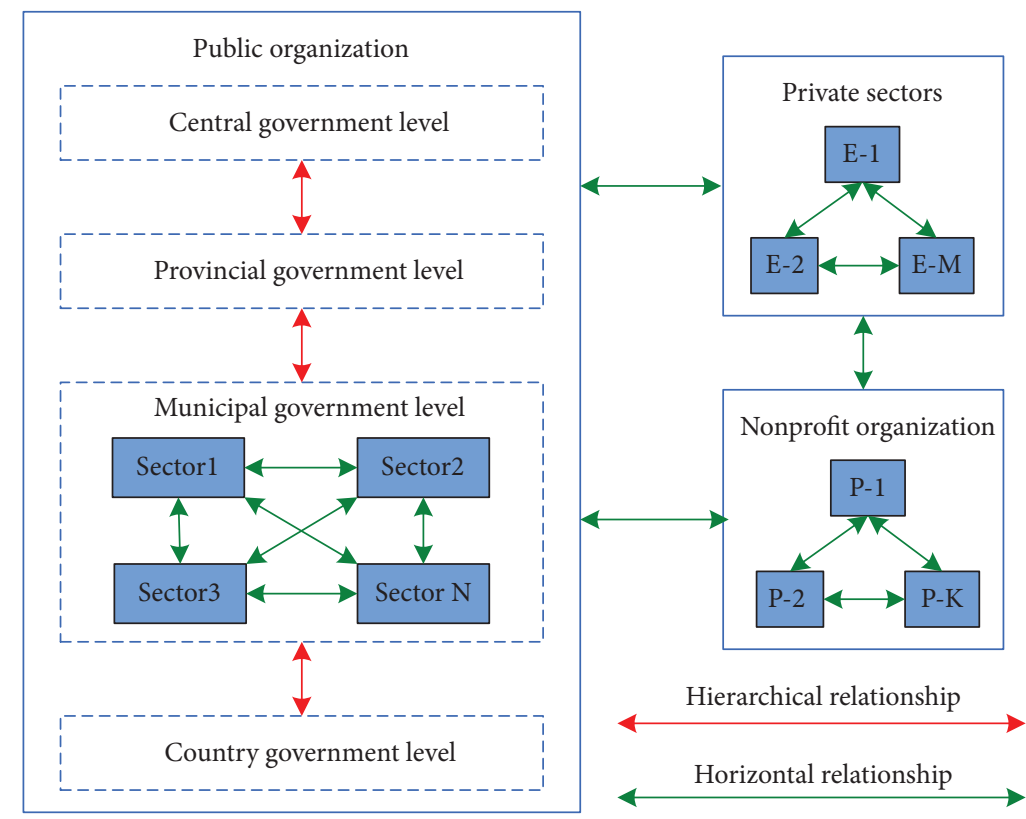

FIGURE 1: The conceptual framework of an intergovernmental and interorganizational network for responding to major accidents.

risk levels which may occur in the jurisdictional area. Furthermore, responsible organizations with similar capacities are arranged in an emergency function group to streamline the emergency services. A number of emergency operation plans have been developed for providing clear ground rules and processing transparency by arranging the response works of participators.

Hierarchically, the political-administrative structure in China consists of four governmental levels: the central, provincial, municipal, and county (or local) levels. The legal emergency management responsibilities of various government levels are specified according to the severity of consequence of emergencies in China. When a jurisdictional government evaluates that addressing the current emergency situation exceeds the capacity of subordinate governments and satisfies the conditions specified in the emergency operation plans, it should activate the established emergency management network in this government level, which is merged with the existing emergency response network for adapting to the disastrous situation. As the disastrous situation evolves and deteriorates, the emergency response network expands as governments in higher levels participate in addressing the emergencies. The layered emergency management institutional arrangement allows for appropriate response scale for each specific emergency.

In the current time, the emergency management network is designed and sustained independently within different government levels. How to leverage and integrate emergency management networks across multiple government levels within critical time constraints toward addressing major accidents together is an existing problem. In addition, the actual emergency response network should take into account the emergent characteristics and include a broad enough spectrum of participators for adapting to the complex emergency situation $[25,26]$.

\section{The Conceptual Framework of the Intergovernmental Emergency Response Network}

During major accidents, an emergency response network consisting of diversified participators emerges and sustains adapting to the disastrous situation. While performing different types of operations, the broad range of participating organizations interact and collaborate with one another across the organizational boundaries, which is essential for achieving successful emergency response. Actually, the involved interorganizational interactions reflect an intriguing mixture of collaboration in both hierarchical and horizontal dimensions. In this section, a conceptual framework of an intergovernmental and interorganizational network is presented for examining the intergovernmental and cross-sectoral collaboration of addressing major accidents as shown in Figure 1. The participating organizations, both the hierarchical and horizontal interorganizational relationships, as well as the involved governance mechanisms [27] of promoting interorganizational collaboration, are discussed. The details are listed as follows.

4.1. Hierarchical Relationships and the Governance Mechanisms. In the context of China, the hierarchical relationships are mainly the interorganizational hierarchies specified by the institutionalized political-administrative structure [28] during emergencies. First, the affiliation relationships between the jurisdictional government and its subordinate sector, such as governmental sectors, stateowned companies, and public institutions, are typical hierarchical relationships. Second, the administrative supervision relationships between governments at various levels and business guidance relationships among the governmental sectors in different government levels belong to this type of 
interorganizational relationships. The top-down administrative system consists of the specified interorganizational hierarchical relationships, and formal authority is extended along with the hierarchies.

On the basis of interorganizational hierarchies, organizations with authorities direct and control multiple subordinate sectors to perform specific operations and resolve possible conflicts in a timely manner. Hierarchy mechanism is an essential governance mechanism to coordinate multiple organizations with these types of interorganizational relationships. The jurisdictional government mobilizes all the subordinate sectors to participate in the response process and achieves rapid coordination at a government level. Meanwhile, among various government levels, public organizations at a lower level are the first to respond to emergencies and report the emergency situation to those at the higher level. Then, the government at the higher level provides external assistance to local governments, as well as coordinates and supervises all subordinate sectors toward addressing a disastrous situation. In China, the provincial and municipal governments play essential roles as a conduit for hierarchical collaboration between central and local governments in large-scale emergency response (Lu, 2016).

\subsection{Horizontal Relationships and the Governance} Mechanisms. Horizontal relationships are those between public organizations without hierarchical relationships, interjurisdictional relationships, and cross-sectoral relationships between public sectors and those from market and society. The interjurisdictional relationships are those among different jurisdictional governments, whereas the other horizontal relationships focus on the broader relationships among organizations without hierarchical relationships, such as those among sectors affiliated with the same jurisdictional government and those among public, private, and nonprofit sectors. Horizontal relationships reflect interaction and exchanges among autonomous organizations, which stress autonomy, partnership, and voluntary agreements. Responding to major accidents creates an atmosphere to develop and improve horizontal relationships, wherein numerous organizations share the common risks and responsibilities. From the institutional arrangement of each government in China, the EMO establishes and sustains the horizontal relationships among organizations with formal emergency management responsibilities for improving information sharing and broad collaboration among all involved sectors in the jurisdiction as discussed in Section 3. The emergency operation plans of addressing accidents specify the formal responsibilities of each involved organization and group them into several emergency function groups for providing streamlined emergency service to impacted communities [29]. Participating organizations affiliated with the same emergency function group establish and maintain horizontal relationships by programing emergency service procedures and excising together toward improving joint decision-making and implementation. Finally, jurisdictional governments at various levels frequently collaborate with one another by signing mutual aid agreements to build interjurisdictional partnerships for sharing information and resource or coping with shared risks efficiently which may spread across administrative boundaries.

Similar to hierarchical collaboration, interorganizational, interjurisdictional, and cross-sectoral collaboration and interaction in the horizontal dimension are also essential to improve effective response in actual emergency situations. However, collaboration across organizational boundaries based on horizontal relationships mainly relies on a network mechanism and market mechanism to arrange the operations of involved sectors. The later one allows participants to use their individual resource to achieve their self-interest, where the former one emphasizes shared value, trust, and consensus in improving interorganizational collaboration and coordination [30]. In particular, network and market mechanisms are essential to mobilize resources beyond the government system and integrate capacities of various sectors from the market and the society toward addressing major accidents.

As per the above discussion, responding to major accidents involves intergovernmental and cross-sectoral interactions and requires effective integration of hierarchical and horizontal relationships that complement each other [3]. Hierarchical, market, and network mechanisms are mixed and embedded in their forms of interorganizational relationships to regulate the behaviors of involved organizations toward improving collaboration and coordination among multiple levels of governments, as well as private and nonprofit sectors. How to leverage and combine each activated emergency management network in various government levels from both hierarchical and horizontal dimensions to regulate diversified interorganizational interactions toward addressing major accident collaboration is an existing problem, particularly in the centralized political-administrative structure in China.

\section{Context, Data Source, and Research Method}

In this research, a case study [31] is conducted to examine the involved intergovernmental and cross-sectoral collaboration during the process of responding to the well-known " 11.22 " Donghuang oil pipeline explosion accident in China from network perspectives. In this case study, the analysis unit is the participating organizations, and various types of interactions across organizational boundaries are recorded for building the actual emergency response network which emerged rapidly after the occurrence of the explosion accident. The case is summarized to provide the context of this study. Furthermore, the data sources and research method are also introduced.

5.1. Context of the Study. At 10:25 pm on November 22nd, 2011, an oil spill occurred at the Donghuang petroleum transmission pipeline, which is located within a highly urbanized and coastal area in the Economy and Technology Development Zone of Qingdao City, Shandong Province, in eastern China. The leaked oil flowed into the municipal pipe network and caused a huge explosion. This accident killed 62 persons and injured 136 others. Furthermore, it caused serious damage to the surrounding construction structures, 
and the water, electricity, heat, and gas supplying systems were destroyed to varying degrees. The leaked oil flowed into the nearby sea through the municipal pipes, caused serious environmental pollution in the coastal region, and were burnt by the explosion, which threatened the safety of the multiple oil tanks in this city. The direct economic losses amounted to nearly 750 million RMB.

The consequences of this accident are evaluated to satisfy the conditions of special major accidents. According to the institutional arrangements of the emergency management system in China as introduced in Section 3, as the accidents occurred and evolved, all of the local, municipal, provincial, and central governments activated emergency management networks in each level in sequence and provided support to the on-scene emergency response operations. Meanwhile, private and nonprofit organizations also participated in the response and recovery process of this accident. Furthermore, a number of emergency response functions are involved, such as firefighting, search and rescue, medical care, cleaning of the oil spill pollution in the coastal and land regions, resettlement of the victims, and repairing of water-, electricity-, gas-, and heat-supplying systems. As a result, responding to this accident involved a broad array of organizations with specific responsibilities and capabilities.

The report [32] issued by the investigation team of the State Council reveals the failure of intergovernmental and interorganizational interaction and collaboration during response to this explosion accident. In particular, poor information reporting and sharing among sectors affiliated with local government and between private and public sectors is the main problems to be identified. Furthermore, the situation assessment and response behaviors of participating organizations are impacted by the interorganizational interactions and caused the disastrous consequences. Therefore, this real-world accident provides an opportunity to examine the intergovernmental and cross-sectoral collaboration by building and analyzing the emerged emergency response network in the context of the Chinese centralized and hierarchical political context. In this research, analyzing the emergency response network of the "11.22" oil pipeline explosion by SNA tools provides an effective way to identify the barriers of integrating all the formal established emergency management networks in each government level and to examine the emerging characteristics of the response process.

5.2. Data Sources. In this research, mixed methods of data collection are conducted to identify the involved participating organizations and interorganizational interactions at varying levels during the response process to the "11.22" oil pipeline explosion accident. All the involved participating organizations are identified and coded by network nodes, while the diversified interorganizational interactions are recorded as network ties for building the emergency response network. First, content analysis of multiple data sources, such as the activated emergency operation plans during response process, newspapers, situation reports, and other reports from official websites and Weibo, was conducted. The detailed explanation of each data source is listed as below.
(1) The Activated Emergency Operation Plans. Emergency operation plans describe the legal roles and responsibilities of each organization and provide guidance for emergency management. The jurisdictional governments at the local, municipal, provincial, and central levels activated relevant emergency operation plans during the "11.22" oil pipeline explosion accident for addressing disastrous situations. Content analysis of these documents was conducted to identify the candidates of participating organizations. As a result, a preliminary list of participating organizations was established.

(2) Official Accident Investigation Report. After the explosion accident occurred, the State Council of China set up an official investigation team and issued an investigation report on January 11th, 2014. This official document described the detailed emergency response process and provide a data source with high reliability, which specifies the main participating organizations and interactions spanning organizational boundaries [32].

(3) Situation Reports from Newspapers, Official Websites, and Weibo. This research also collected related reports from Qingdao Daily, Qingdao Evening Daily, and Qingdao Morning Daily. Related electronic media reports from the official website and Weibo of the provincial, municipal, and local government sectors were selected as an authoritative source of trusted information to track the emergency response process and to collect data of network nodes and ties.

Second, in-depth interviews of key informants were conducted to complement with the primary data sources. Numerous public organizations at the municipal and county government levels participated in the emergency response process in this case. Two emergency managers from the Emergency Management Office of Qingdao City, which are responsible for managing the emergency management network at the municipal government level, were interviewed. In addition, six managers from sectors affiliated with the Government of Qingdao Economic and Technological Development Zone were interviewed to investigate the participating organizations and the involved types of interorganizational interactions. The first-hand data complements with the aforementioned second-hand data sources.

5.3. Research Method. For examining the intergovernmental and cross-sectoral collaboration among all the participating organizations, network analysis was conducted to identify the structural patterns of their relationships and to analyze the effects of the network structure on the response behaviors of participators [33]. This research applied the SNA software tool Netminer [34] to model and visualize the involved organizations and their interorganizational relationships in both hierarchical and horizontal dimensions during the responding process to the "11.22" explosion accident. Meanwhile, the SNA indicators were applied to measure the network structure at the levels of the node, subset of nodes, and whole 
network. Furthermore, how the network structure characteristics affect behaviors of involved organizations was discussed, and the managerial implications were provided. The involved network metrics, such as network density, centrality analysis, and structural block analysis, are focused on and introduced as follows.

Network density indicates the degree to which a network is cohesive. The SNA measures, such as density and centralization, can be applied to depict the network structural properties. The density is defined as the number of existing ties between organizations, with respect to the maximum number of possible ties.

Centrality measure is used to identify the key actors in the network or describe the nodes' position or roles. This indicator reveals interesting characteristics about the network. The centrality analysis includes degree centrality, betweenness centrality, closeness centrality, and effect centrality [33]. Degree centrality analysis can be performed to identify which organization interacts directly with another in the network. Betweenness centrality is an indicator of the extent to which a network actor locates within the shortest distance between a pair of nodes in the network [33]. Its value ranges from 0 to 1. The higher betweenness centrality value for a network actor indicates that it can better control the information communication of other nodes in the network. The effect centrality of a given node is the measure of the effect strength from this node to all the other ones through every path between them. It fully captures the concept of embeddedness because it considers both direct and indirect links. Therefore, we believe that this concept is a more accurate indicator of the extent to which an organization is embedded in the network structure comparing with the degree centrality, which only considers the local area of the network.

In social network analysis, all the nodes can be divided into different exclusive subsets, called positions. Structural block analysis can be employed to describe the interactive relationships among positions [33]. The produced block model is an abstract representation of the entire network. For each pair of positions, the structural block analysis reports whether the ties are present or absent within or between those pairs. Moreover, the density of a given interactive relationship is the ratio of the number of present lines to the maximum number of possible ones.

\section{Building and Analyzing an Emergency Response Network for Major Accidents}

Responding to major accidents is a highly complex process that involves numerous response tasks that should be completed to achieve common incident objectives. An emergency management network consists of diversified organizations performing different tasks and interacting with one another. The interactions and exchanges spanning organizational boundaries are of varying levels and difficult to identify, thereby presenting obstacles to build the emergency response network. The content analysis of the aforementioned data sources was conducted to identify interorganizational activities for building an emergency response network of addressing the "11.22" oil pipeline explosion accident. In fact, it is an intergovernmental, cross-sectional, and interjurisdictional network for adapting to the complex disastrous situations. Network analysis based on the SNA tool Netminer [34] is employed to visualize, measure, and decipher the network. The involved interorganizational collaborative process is analyzed and understood from network structural perspectives. This section introduces the approach of identifying response organizations and defining the boundary of the emergency response network. Also, how to evaluate interorganizational collaborative relationships in the institutional context of China by tracking the interaction among organizations during emergencies is presented. Finally, the emergency response network is visualized and analyzed for examining characteristics of the involved intergovernmental and crosssectoral collaborative process.

6.1. Identifying the Response Organizations. Identifying organizations that participated in the actual emergency response process of the "11.22" oil pipeline explosion accident is the first step to build the emergency response network. Major accidents cause disastrous consequences and require a broad range of response organizations to perform diversified tasks toward achieving common objectives. The emergency response process increasingly involves close interactions across an array of sectors and different government levels [35]. Moreover, the actual emergency response tends to involve an unpredictable set of organizations rather than follow expectations in the documented emergency operation plans [36]. Therefore, identifying all participating organizations and specifying network boundary remain as dilemmas in the field of emergency response [37].

The operational criteria for inclusion in this research requires member organizations to perform tasks or to provide resources for achieving common objectives of addressing the studied accident. First, the candidate participating organizations were identified by content analysis of the activated emergency operation plans at each government level, and then the preliminary response organization list was formed. These organizations have formal emergency management responsibilities, and most of them are from the public sector. However, the emergency response demonstrates the emergent properties [25]. Most of the private and nonprofit organizations were not listed in the emergency operation plans but actually participated in the emergency response and contributed to the achievement of incident objectives. Thus, all other data sources were utilized to verify whether organizations in the preliminary list actually responded to disastrous situations and to identify other organizations which satisfy the abovementioned operational criteria of network members. Several new organizations were added to the initial organization list. Finally, a total of 209 organizations which participated in the response process to the "11.22" oil pipeline explosion were identified as shown in Table 1. Each organization was recorded as a separate entity, and multiple attributes were encoded, such as organization number, name, organizational type, responsibilities, and the main performed tasks. All the response organizations were classified as belonging to either the public, private, or nonprofit sector. In addition, the public sectors affiliated with 
TABLE 1: The organizations responding to the "11.22" oil pipeline explosion.

\begin{tabular}{lcc}
\hline Organization type & Number & Percentage \\
\hline Public organization & & \\
Central level & 8 & $3.8 \%$ \\
Provincial level & 10 & $4.8 \%$ \\
Municipal level & 34 & $16.3 \%$ \\
County level & 37 & $17.7 \%$ \\
Private organization & 65 & $31.1 \%$ \\
Nonprofit organization & 55 & $26.3 \%$ \\
All organizations & 209 & $100 \%$ \\
\hline
\end{tabular}

various government levels consist of government sectors, state-owned companies, and public institutions.

6.2. Evaluating Interorganizational Relationships. During emergency response, all the participating organizations interact with one another by conducting diversified activities spanning an organization's boundaries. Interorganizational relationships describe which participating organizations interact with one another and provide abstract representation of multiple types interorganizational interaction, such as issuing orders and making commitments; information reporting; providing resource, service, and expertise; information sharing; joint decision-making by attending meetings; sharing resource and knowledge; and working together when performing common tasks. In this research, the interorganizational relationships are determined by identifying interactive activities across the organization's boundaries. The content analysis of the aforementioned data sources in Section 5.2 which records the emergency response process was conducted to evaluate the interorganizational relationships.

As discussed in Section 4, interorganizational relationships among all the participators consist of hierarchical and horizontal relationships. Hierarchical relationships are established and sustained before emergencies and reflect the hierarchy mechanism. As formal network ties, the preliminary list of hierarchical relationships among participating organizations was identified according to the institutional hierarchical arrangements in the emergency management system in China. Furthermore, each hierarchical relationship in the list is verified by identifying interactive activities of issuing orders and making commitments and reporting information among the participating organizations in the actual response process. Only those representing actual interactions spanning organizational boundaries were retained in the list. On the other hand, interorganizational relationships in the horizontal dimension are conceptualized as a representation of interactive activities among the identified participating organizations without hierarchical arrangements. Most of the emergent interorganizational interactions belong to this type. A context analysis of data sources was conducted to identify collaborative activities across organizational boundaries, such as issuing orders, making commitments, information reporting and reception, for determining whether there exist horizontal relationships among the participating organizations. Unlike hierarchical relationships, horizontal ones are determined by formal collaborative arrangements and emergent interorganizational interaction and exchanges during emergencies.

In this research, a total of 141 hierarchical relationships and 521 horizontal relationships among the 209 participating organizations were identified and verified. The hierarchical relationships function as stronger network ties compared with the horizontal ones. Both types of relationships complement each other and simultaneously improve collaboration and coordination among all the participating organizations by applying different governance mechanisms as discussed in Section 4.

6.3. Visualizing the Emergency Response Network. Effective response to major accidents depends on the integration of all the involved partners, which interact with one another during emergencies. All response organizations should understand their respective roles and responsibilities, as well as how to complement each other toward achieving common incident objectives. The emergency response network of the "11.22" oil pipeline explosion accident is built and shown in Figure 2 based on the identified participating organizations and interorganizational relationships. This interorganizational network consists of 209 organizations, with 141 links representing hierarchical relationships and 521 links representing horizontal ones. This actual emergency response network comprises a combination of organizations from local, municipal, provincial, and central government levels, as well as private and nonprofit organizations. In addition, interorganizational relationships in both hierarchical and horizontal dimensions interweave with each other, and the underlying governance mechanisms complement each other contributing to improve the coordination and collaboration among the involved response organizations [38]. The whole network is integration of all the activated emergency management networks in each government level, as well as the emergent nodes and dyadic ties.

6.4. Analyzing and Deciphering the Network Structure. The emergency response network of the "11.22" oil pipeline explosion accident exhibits interorganizational interactions in both hierarchical and horizontal dimensions; it shapes the actual collaborative process among all the response organizations in the Chinese institutional environment of emergency management. In this section, the quantitative metrics in SNA are used to analyze the emergency response network. The characteristics of the emergency response network are examined at the levels of the whole network, subnetwork, and node. In addition, how the network characteristics impact the behaviors of these participating organizations is analyzed and discussed.

6.4.1. Characteristics of the Whole Network. The density of the aforementioned emergency response network is 0.031 , and its average degree is 6.396. Those network analysis results indicate that one organization interacts with an average of six organizations. Network density also shows the sparse characteristic of the emergency response network. 


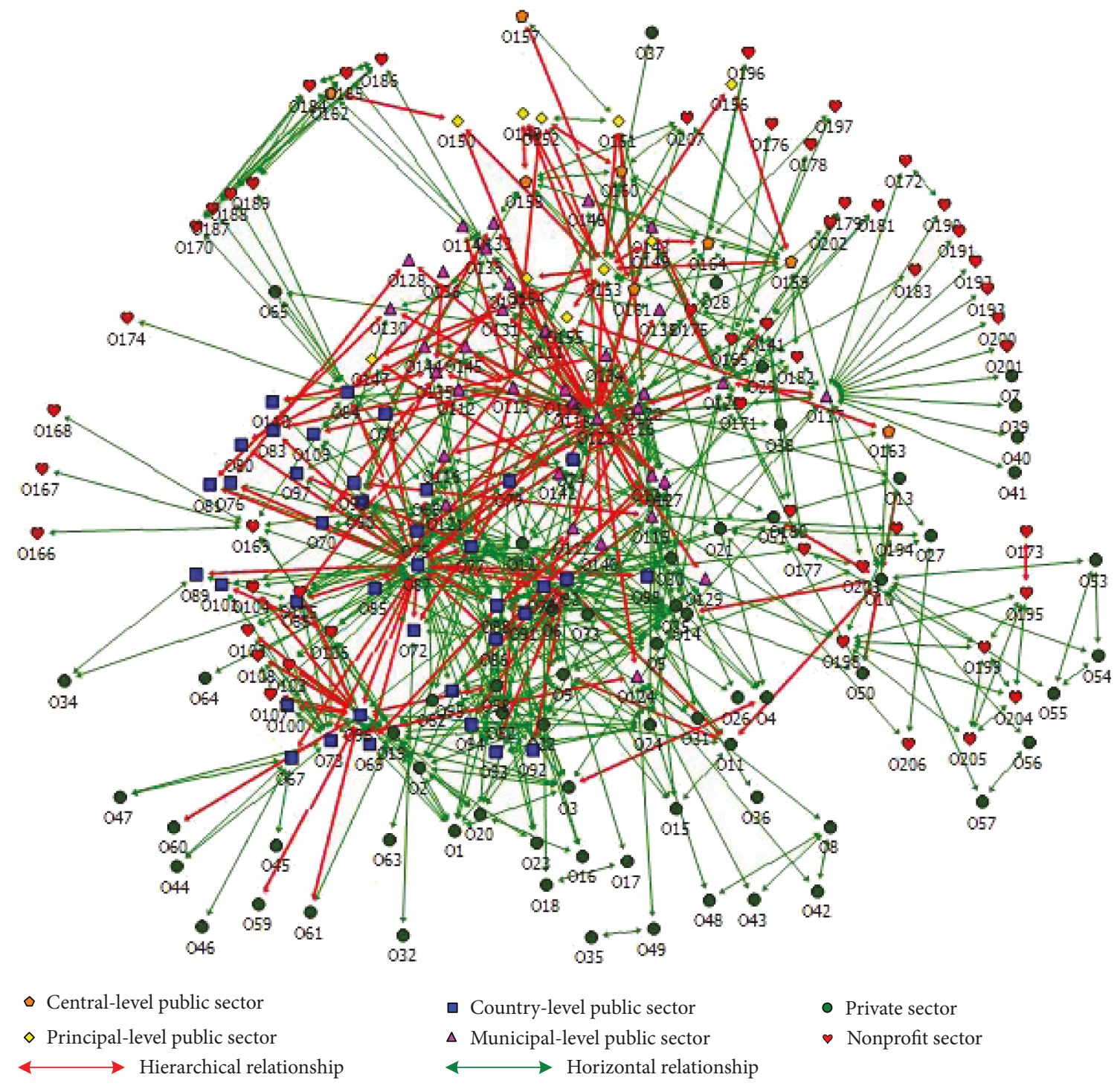

FIGURE 2: Emergency response network of the "11.22" oil pipeline explosion.

6.4.2. Centrality Analysis. Centrality analysis is used to analyze the embeddedness of nodes in the network. As an important network metric, it determines access to and control over resources and information in the network structure. Analyzing how a response organization is embedded into the whole emergency response network is an effective way to understand its behaviors during emergencies.

(1) Degree Centrality Analysis. Figure 3 presents a concentric map of degree centrality. The greater the degree centrality value of the response organization is, the closer its location to the center of the map. Table 2 shows the 10 response organizations with the highest degree centrality value. Figure 3 indicates that most of the private sector and nonprofit organizations is located at the periphery. The response organizations in the core are mainly the public organizations. In particular, public organizations are mainly from the municipal and district government levels. The municipal and district governments and sectors affiliated with them are the main response organizations in the actual emergency response process of this major accident.

Table 2 shows that EMOs of Huangdao District (O87) and Qingdao District (O123) keep interaction with most organizations during emergencies. In the top 10 organizations with high degree centrality value, 6 are from the district government level, whereas the remaining 4 are municipal government level ones.

(2) Betweenness Centrality Analysis. Table 3 shows the top 10 organizations with the highest betweenness centrality. With the exception of response organization O10, all the organizations are public organizations at the district, municipal, and provincial government levels. In particular, the EMOs of the Qingdao Municipal Government (O123) and Huangdao District Government have higher betweenness centrality value than the other organizations. This result indicates that 


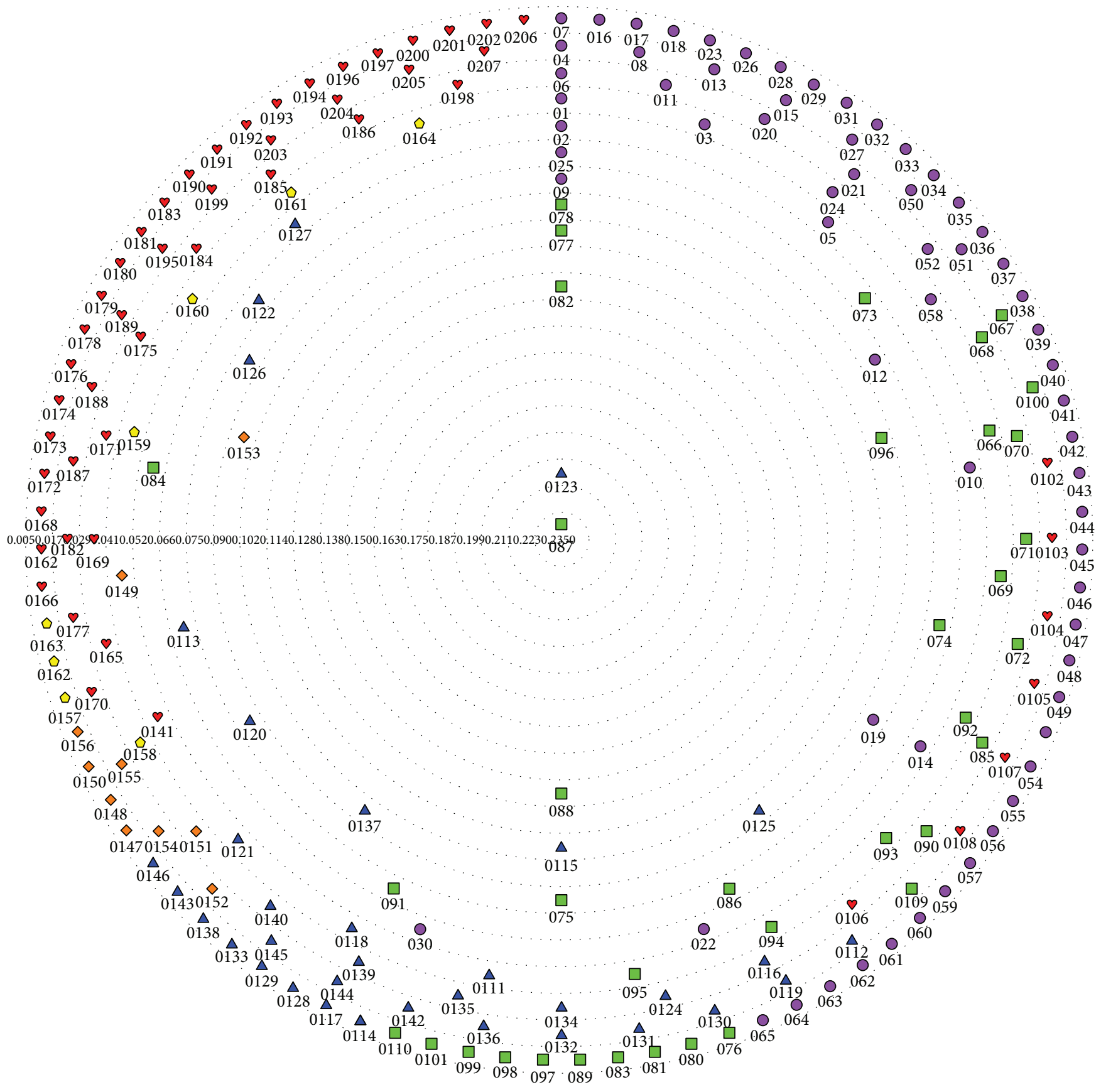

Figure 3: Concentric map of the response organizations.

the EMO at the municipal and district levels of the government are the information hubs, which play essential roles in collecting and disseminating information.

(3) Effect Centrality analysis. The weight parameter is set to be 0.6 in the effect centrality analysis in this study, which defines the transmitted effect of indirect links on the direct link. The ten response organizations with the highest effect centrality are listed in Table 4. As shown, five response organizations are public organizations at the district government level, four organizations are from the municipal government level, and only one is from the provincial government level. The effect centrality analysis shows that public organizations have a stronger impact on the whole network.

6.4.3. Structural Block Analysis. In this section, the whole characteristics of the emergency response network are examined. Each position represents a mutually exclusive subset of organizations with the same organizational attribute. The block model presents interactive ties among all the positions, which provides an effective way to examine characteristics of the emergency response network.

(1) Block Analysis of Organizational Types. As discussed in Section 2, each jurisdictional government establishes and 
TABLE 2: Ten organizations with the highest degree centrality.

\begin{tabular}{lccc}
\hline Rank & Organization code & Organization name & Degree centrality \\
\hline 1 & O87 & EMO of the Huangdao District Government & 0.2476 \\
2 & O123 & EMO of the Qingdao Municipal Government & 0.2184 \\
3 & O88 & Huangdao District Public Works Administrative Departments & 0.1359 \\
4 & O82 & Huangdao District Firefighting Bureau & 0.1262 \\
5 & O77 & Huangdao District Police Bureau & 0.1068 \\
6 & O115 & Qingdao Municipal Firefighting Bureau & 0.1068 \\
7 & O78 & Huangdao District Environment Protection Bureau & 0.0971 \\
8 & O96 & Huangdao Street Office & 0.0971 \\
9 & O125 & Qingdao Municipal Health Bureau & 0.0971 \\
10 & O137 & Qingdao Municipal Central Blood Station & 0.0971 \\
\hline
\end{tabular}

TABle 3: Ten organizations with the highest betweenness centrality.

\begin{tabular}{lccc}
\hline Rank & Organization code & Organization name & Betweenness centrality \\
\hline 1 & O123 & EMO of the Qingdao Municipal Government & 0.3132 \\
2 & O87 & EMO of the Huangdao District Government & 0.2707 \\
3 & O137 & Qingdao Municipal Central Blood Station & 0.1213 \\
4 & O88 & Huangdao District Public Works Administrative Departments & 0.0961 \\
5 & O125 & Qingdao Municipal Health Bureau & 0.0642 \\
6 & O115 & Qingdao Municipal Firefighting Bureau & 0.0614 \\
7 & O124 & Qingdao Municipal Business Bureau & 0.0597 \\
8 & O84 & Huangdao Municipal Education Management Bureau & 0.0564 \\
9 & O153 & EMO of the Shandong Principal Government & 0.0558 \\
10 & O10 & China Petroleum and Chemical Corporation & 0.0515 \\
\hline
\end{tabular}

TABLE 4: Ten organizations with the highest effect centrality.

\begin{tabular}{lccc}
\hline Rank & Organization code & Organization name & Effect centrality \\
\hline 1 & O123 & EMO of the Qingdao Municipal Government & 0.0233 \\
2 & O87 & EMO of the Huangdao District Government & 0.0230 \\
3 & O137 & Qingdao Municipal Central Blood Station & 0.0210 \\
4 & O125 & Qingdao Municipal Health Bureau & 0.0124 \\
5 & O88 & Huangdao District Public Works Administrative departments & 0.0102 \\
6 & O96 & Huangdao Street Office & 0.0099 \\
7 & O153 & EMO of the Shandong Principal Government & 0.0098 \\
8 & O77 & Huangdao District Police Bureau & 0.0096 \\
9 & O115 & Qingdao Municipal Firefighting Bureau & 0.0092 \\
10 & O82 & Huangdao District Firefighting Bureau & 0.0089 \\
\hline
\end{tabular}

sustains an emergency management network for facilitating collaboration among involved organizations in jurisdictional areas. In this research, the response organizations are grouped into six groups, such as public organization groups at the central, provincial, municipal, and county government levels, a private organization group, and a nonprofit organization group. Addressing "11.22" oil pipeline explosion requires effective collaboration and coordination among all of these groups. However, the motivations, institutional logic, and accountability mechanisms of response organizations affiliated with these groups are different, which impacts the behaviors and interorganizational interaction during emergency response [28].

Figure 4 presents the interactive relationships among and within blocks representing the above groups. The lines represent interactive relationships and the width and color of the lines represent the density of network ties, so that a wider and darker line indicates a higher density of ties among or within groups. As shown in Figure 4, public organizations affiliated with different government levels prefer to interact 


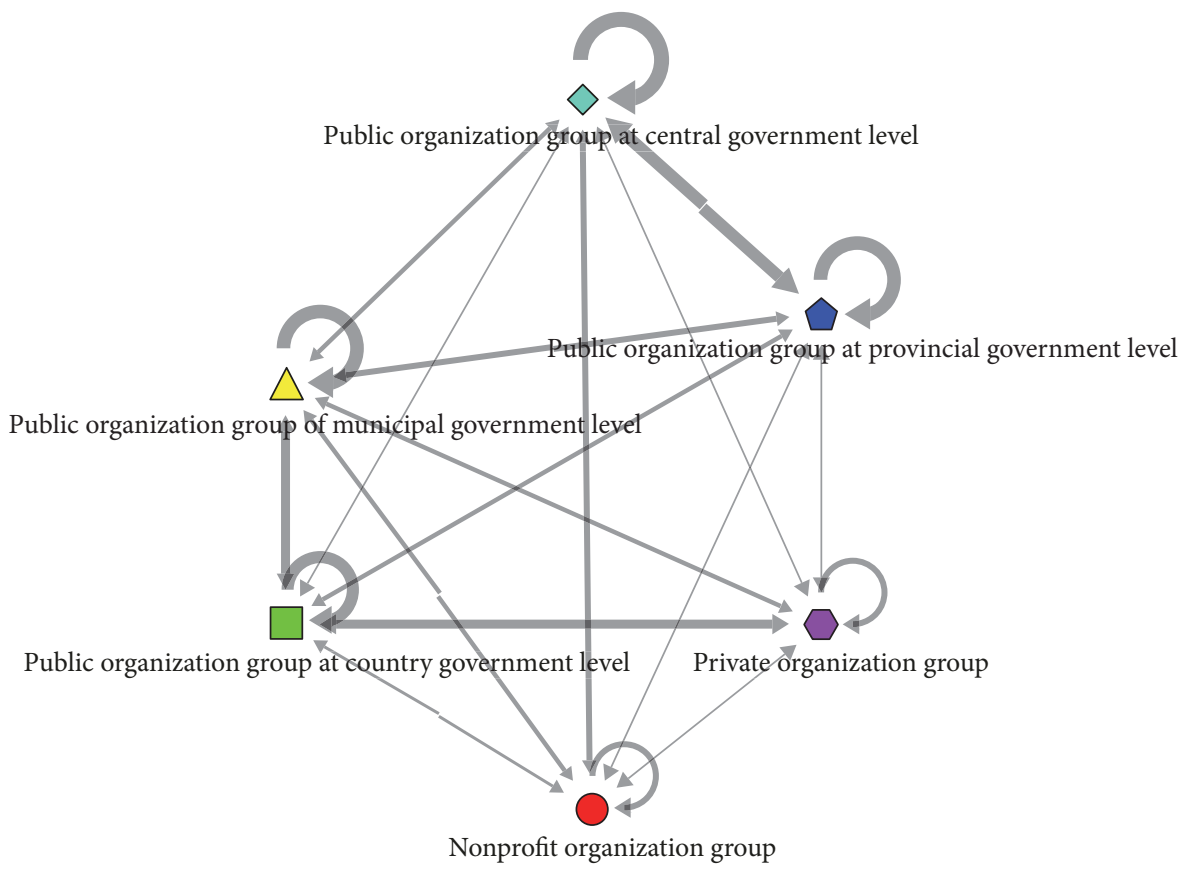

FIGURE 4: Block model of response organization type.

with other ones in the same group. The phenomena indicate that the established emergency management networks in each government level improves interorganizational collaboration among public organizations effectively. In addition, the analysis result indicates that public organizations at the same government level pay more attention to collaborating with each other in the same group than with private and nonprofit organizations and reflects that the cross-section horizontal relationships among public, private, and nonprofit organizations are not established, maintained, and nurtured at the current time. The existing intergovernmental interactions are mainly between jurisdictional governments at adjacent levels. In fact, that reflects the hierarchical structure among public organizations affiliated with different government levels and shows that the political-administrative system of the Chinese government plays essential roles in facilitating intergovernmental collaboration and coordination during this major accident. The private organizations tend to collaborate with organizations within the same group and public organizations at the county government level, which is at the bottom of the Chinese government system. The interactive relationships between private organizations and public organizations at the central, provincial, and municipal government levels are lacking. Finally, close interactions and links between nonprofit sectors and all other response organizations are lacking. That reduces the collaboration level and emergency response effectiveness.

(2) Block Analysis of Emergency Function Groups. Similarly, the response organizations can also be grouped into multiple exclusive subsets representing different emergency functions [16]. Response organizations affiliated with an emergency function group have specific capabilities for providing a specific emergency service. Moreover, emergency services provided by various emergency function groups complement one another and should be integrated to address the disastrous situation together. During response process of the "11.22" oil pipeline explosion accident, each emergency function group collaborates with others to provide continuous and coordinated emergency services to achieve common incident objectives, such as saving human lives, protecting properties and the environment, stabilizing the incident, restoring basic services and community functions, and establishing a safe and secure environment for transition to recovery. All the participating organizations are classified into 15 groups in this research. Each group provides specific emergency response functions and performs relevant tasks during the emergency response process, as detailed in Table 5. In addition, the affected communities which received emergency service and provide self- and mutual aids to victims are defined as a specific group for conducting structural block analysis. In this research, structural block analysis determines whether interactive relationships exist among these blocks representing emergency function groups.

Figure 5 presents the block model showing interactive relationships within and among blocks representing emergency function groups. Similar to Figure 4, the lines represent the interactive relationships between different emergency function groups or among response organizations within the same group. The width and color of the lines represent the density of network ties, so that a wider and darker line indicates a higher density of ties among or within the emergency function group. From Figure 5, response organizations affiliated with the emergency function groups Resident Resettlement, Psychological Intervention and Mass Care, 
TABLE 5: The involved emergency function groups responding to the "11.22" oil pipeline explosion.

\begin{tabular}{|c|c|}
\hline Emergency function group & Task description \\
\hline Traffic Control & Manage the traffic \\
\hline Transportation & Transport materials to the accident scene \\
\hline Resident Resettlement & Provide house and food to evacuated residents \\
\hline Information Issue and Media Management & $\begin{array}{c}\text { Issue emergency information to the public and } \\
\text { manage the media personnel on scene }\end{array}$ \\
\hline Information Monitoring & Collect, analyze, and distribute emergency situation information \\
\hline Public Works and Engineering & Restore and repair electricity, water, and gas supply systems \\
\hline Emergency Medical Care & Provide medical care to victims \\
\hline Psychological Intervention and Mass Care & Provide mental health service to victims \\
\hline Emergency Command and Coordination & $\begin{array}{l}\text { Coordinate incident management and response efforts, } \\
\text { issue mission assignments, and plan the emergency response }\end{array}$ \\
\hline Firefighting and Search and Rescue & $\begin{array}{l}\text { Search for and rescue victims in the accident; extinguish fire } \\
\text { caused by the explosion in the accident }\end{array}$ \\
\hline Life Material Support & Provide life materials to the evacuated residents \\
\hline Oil and Hazardous Material Response & Clear the pollution caused by the oil spill on land and in the sea \\
\hline Guarding and Public Security & Block the scene of the accident and maintain public order \\
\hline Communication Support & Maintain and restore telecommunication infrastructure \\
\hline
\end{tabular}

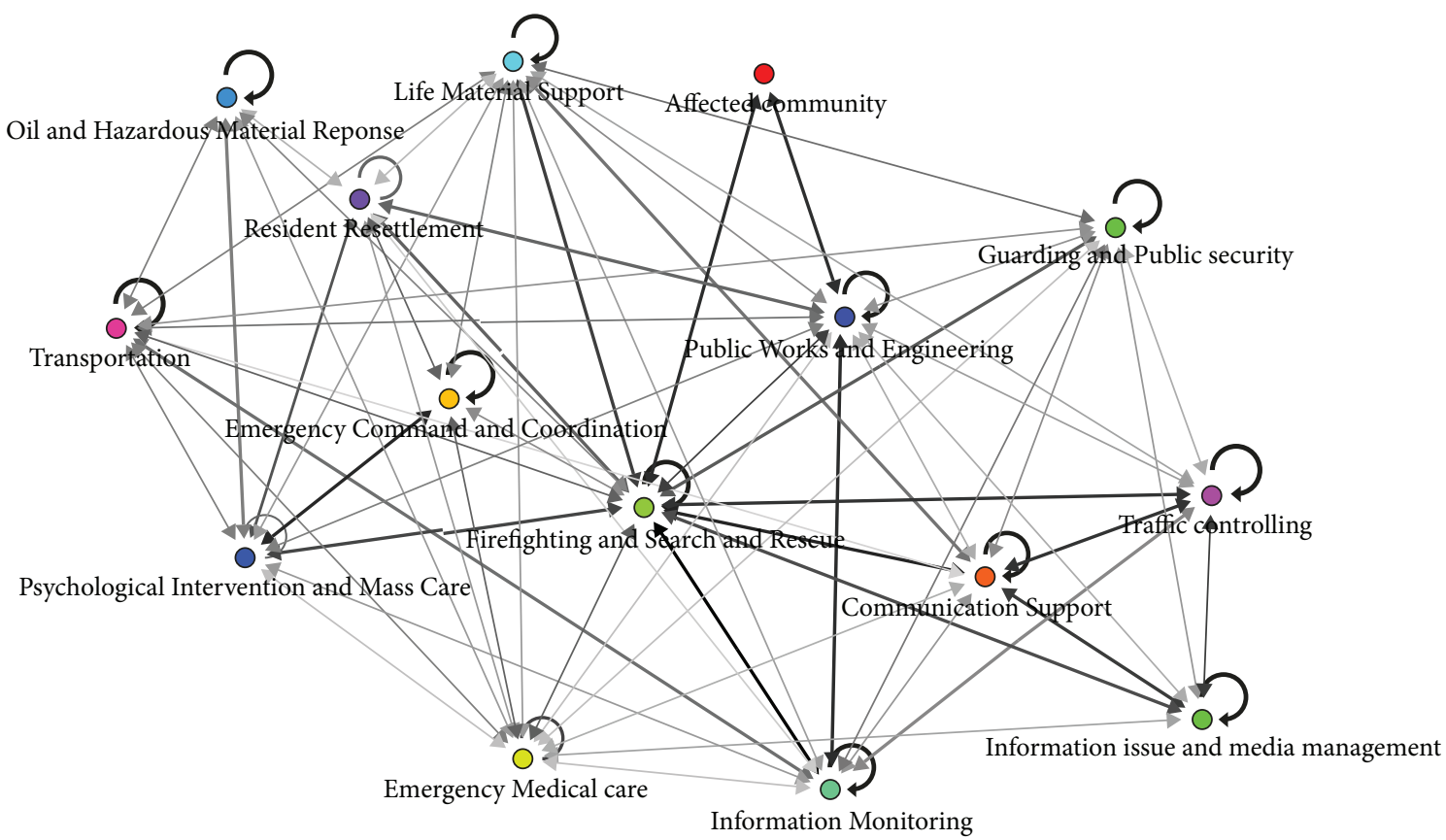

FIGURE 5: Block model of emergency response function groups.

and Emergency Medical Care, interact with each other at a low level, and the interorganizational relationships among organizations affiliated with the same groups should be improved to provide more streamlined emergency response services. As the core of the whole network, there does not exist dense interactive relationships between the block representing the Emergency Command and Coordination group and other groups. That indicates that the former groups cannot coordinate response organizations in the other group to achieve better network collaboration. Especially, there are no interactive relationships between the Emergency Command and Coordination group and the Affected Community group. This observation indicates that information about the disastrous situation and consequences of this explosion cannot be collected rapidly and effectively during the emergency response. Therefore, that presents barriers to the interorganizational collaboration in the emergency response process. 


\section{Discussions and Managerial Suggestions}

Intergovernmental and interorganizational collaboration taking the form of network ties among response organizations is necessary to successfully address major accidents and determine the performance of emergency response to a great extent. The networked response operations spanning organizational boundaries are a highly complex assembly of multiple heterogeneous organizations with different capabilities and functions for achieving common objectives. Reflecting on the response to the "11.22" oil pipeline explosion accident, responding to a major accident requires that public organizations affiliated multiple government levels, as well as private and nonprofit organizations, collaborate and interact with one another, while still performing tasks within the boundaries of their own organization. Appropriate structure is a necessary condition for achieving network effectiveness. A number of managerial suggestions are drawn from examining constituents and structural characteristics of an actual emergency response network for the " 11.22 " oil pipeline explosion accident in China but can also be relevant to improve the existing emergency management system in the centralized political-administrative context.

First, in the participating organizations, $31.1 \%$ are private organizations, while $26.3 \%$ are from the nonprofit sector. Thus, both private and nonprofit organizations play essential roles for addressing major accidents. However, the existing emergency management network at each government level emphasizes the responsibilities and functions of public organizations in emergency response and neglects the participation of the private and nonprofit sectors. The governments should plan ahead to effectively establish and sustain partnerships between other public, private, and nonprofit organizations for integrating their capabilities into the existing emergency management systems at each government level.

Second, from the centrality analysis, public organizations at the county and municipal government levels play the most important roles in addressing major accidents and are located at the central position in the emergency response network. The network analysis results show that governments at the county and municipal government levels do not only rapidly respond to major accidents but also play more important roles than the principal and central governments. Furthermore, from the structural block analysis in Section 6.4.3, the interactive relationships between private and public organizations at the central, provincial, and municipal government levels are weaker than those between private and public sections at the county government level. During response to major accidents, the participating organizations at the local government level are faster than others and are more active than others to coordinate their response operations. Therefore, network leadership capability of local governments should be focused on and enhanced for a successful response to major accidents. The important lesson from this empirical research indicates that more investment should be made at the local government level in the field of emergency management.

Third, despite network mechanism being considered as an alternative to the hierarchy mechanism, this case study reveals that a blend of hierarchical, market, and network principles and strategies is mixed in fostering intergovernmental and interorganizational collaboration during response to major accidents in China. The involved multiple governance mechanisms are embedded in the form of diversified links spanning organizational boundaries as shown in the map of an emergency response network in Section 6.2. These governance mechanisms complement each other for improving the effectiveness of the emergency response network. In particular, the shadow of interorganizational hierarchies is apparent in the network according to the structural block analysis of organizational types in Section 6.4.3. That reveals that the political-administrative system of the Chinese government plays essential roles in the networked response operations for addressing major accidents. In fact, it facilitates rapid collaboration and coordination in these intergovernmental and interorganizational network environments during emergencies.

Finally, participating organizations affiliated with the same emergency function group should interact with each other to provide specific emergency services in this empirical research. Moreover, all the fourteen emergency function groups involved in the responding process are required to keep interaction and collaboration with each other for providing streamlined services to affected communities and achieving better network effectiveness. As discussed in Section 6.4.3, a number of problems are identified from the block analysis of emergency function groups, which provides guidance to improve the design of emergency function groups in the involved emergency operation plans. For example, organizations affiliated with the emergency function groups Resident Resettlement, Psychological Intervention and Mass Care, and Emergency Medical Care should pay more attention to establish and sustain partnerships with each other. The interactive relationships between the Emergency Command and Coordination group and those in other groups are weak and should be improved. In particular, the information reporting relationships from the affected communities to organizations affiliated with the Emergency Command and Coordination group should be established and strengthened for collecting information on disastrous situations and identifying response requirements more exactly and quickly.

\section{Conclusions and Future Work}

Intergovernmental and multiorganizational collaboration for addressing major accidents involves complex interactions spanning organizational boundaries of public sectors in multiple government levels, as well as private and nonprofit sectors. Despite the institutionalized emergency management systems having been established in the last decade, the lack of interorganizational collaboration and coordination presents challenges to Chinese governments for responding to emergencies involving multiple government levels. In this research, the whole picture of intergovernmental and cross-sectoral collaboration in responding to the wellknown oil pipeline explosion accident is focused on and examined from network perspectives to obtain managerial 
insights in improving the existing emergency management system in the centralized political-administrative context, such as China.

By conducting mix data collection methods, all the participating organizations and numerous interorganizational relationships in both hierarchical and horizontal dimensions are identified. The emergency response network is built to represent the interorganizational collaboration of varying types involved in the response process. The research facilitates the development of theoretical linkages between the emergency response concepts and social network analysis. From quantitative analysis results of the emergency response network based on SNA, a number of findings and managerial suggestions for improving the existing emergency management system in China are proposed. First, the Chinese government should pay attention to establish and sustain partnerships with private and nonprofit organizations, and a blend of hierarchical, market, and network principles and strategies should be mixed to complement one another in fostering collaboration among responsible organizations in the emergency management system in China. Second, the participating organizations at the local government level are faster in responding to accidents and are more active than other participators in coordinating their response operations. The capabilities of local governments should be emphasized in emergency management. Finally, the interactive relationships among specific emergency function groups and between the possible affected communities and organizations performing the emergency command and coordination function should be strengthened. Although we focus on a case study of a major explosion accident, this research provides insights on how to improve the intergovernmental collaboration involved in addressing complex problems in the centralized political-administrative context.

The main limitations of the reported research pertains to the data sources. Tracking real-world intergovernmental collaboration to identify all the organizations in the network boundaries and to determine interorganizational relationships of varying types is an existing problem. Furthermore, this study focuses on static networks by capturing interactions during the entire response process and disregards the evolution of the emergency response network over time. Actually, the intergovernmental and cross-sectoral response to large-scale emergencies can be reframed as a dynamic and adaptive network that adjusts for best fitting the demands of ever-changing disastrous situations. The future work is to conduct research on the evolution of emergency response networks.

\section{Data Availability}

The data used to support the findings of this study are available from the corresponding author upon request.

\section{Conflicts of Interest}

The authors declare that there is no conflict of interest regarding the publication of this paper.

\section{Acknowledgments}

The work was supported by the National Science Fund of China (Project Nos. 71774068 and 71303093), the Humanities and Social Science Youth Fund of the Ministry of Education in China (Project No. 13YJC630145), the National Science Fund of Guangdong Province (Project Nos. 2014A030310401 and 2015A030313321), and the Fundamental Research Funds for the Central Universities of China (Project No. 21612301).

\section{References}

[1] L. K. Comfort and N. Kapucu, "Inter-organizational coordination in extreme events: the World Trade Center attacks, September 11, 2001," Natural Hazards, vol. 39, no. 2, pp. 309-327, 2006.

[2] L. K. Comfort, "Managing intergovernmental responses to terrorism and other extreme events," Publius, vol. 32, no. 4, pp. 29-50, 2002.

[3] D. P. Moynihan, "The network governance of crisis response: case studies of incident command systems," Journal of Public Administration Research and Theory, vol. 19, no. 4, pp. 895915, 2009.

[4] N. Kapucu, T. Arslan, and M. L. Collins, "Examining intergovernmental and interorganizational response to catastrophic disasters: toward a network-centered approach," Administration \& Society, vol. 42, no. 2, pp. 222-247, 2010.

[5] J. M. Brooks, D. Bodeau, and J. Fedorowicz, "Network management in emergency response:articulation practices of state-level managers-interweaving up, down and sideways," Administration \& Society, vol. 45, no. 8, pp. 911-948, 2012.

[6] A. Boin and F. Bynander, "Explaining success and failure in crisis coordination," Geografiska Annaler, vol. 97, no. 1, pp. 123-135, 2016.

[7] N. Kapucu and V. Garayev, "Designing, managing, and sustaining functionally collaborative emergency management networks," The American Review of Public Administration, vol. 43, no. 3, pp. 312-330, 2012.

[8] X. Lu and L. Xue, "Managing the unexpected: sense-making in the Chinese emergency management system," Public Administration, vol. 94, no. 2, pp. 414-429, 2016.

[9] F. A. Osman, A. M. Shahan, and F. Jahan, "Managing natural disasters in Bangladesh: activating the network approach," Public Organization Review, vol. 15, no. 1, pp. 99-116, 2015.

[10] T. E. Drabek, Emergency Management: Strategies for Maintaining Organizational Integrity, Springer-Verlag, New York, NY, USA, 1990.

[11] X. Guo and N. Kapucu, "Examining collaborative disaster response in China: network perspectives," Natural Hazards, vol. 79, no. 3, pp. 1773-1789, 2015.

[12] K. Jung and M. Song, "Linking emergency management networks to disaster resilience: bonding and bridging strategy in hierarchical or horizontal collaboration networks," Quality \& Quantity, vol. 49, no. 4, pp. 1465-1483, 2015.

[13] N. Kapucu and F. Demiroz, "Measuring performance for collaborative public management using network analysis methods and tools," Public Performance \& Management Review, vol. 34, no. 4, pp. 549-579, 2011.

[14] M. P. Mandell and R. Keast, "Evaluating the effectiveness of interorganizational relations through networks: developing a 
framework for revised performance measures," Public Management Review, vol. 10, no. 6, pp. 715-731, 2008.

[15] K. G. Provan, A. Fish, and J. Sydow, "Interorganizational networks at the network level: a review of the empirical literature on whole networks," Journal of Management, vol. 33, no. 3, pp. 479-516, 2007.

[16] N. Kapucu and Q. Hu, "Understanding multiplexity of collaborative emergency management networks," The American Review of Public Administration, vol. 46, no. 4, pp. 399-417, 2016.

[17] W. L. Waugh and G. Streib, "Collaboration and leadership for effective emergency management," Public Administration Review, vol. 66, no. s1, pp. 131-140, 2006.

[18] O. Noran, "Collaborative disaster management: an interdisciplinary approach," Computers in Industry, vol. 65, no. 6, pp. 1032-1040, 2014.

[19] J. M. Bryson, B. C. Crosby, and M. M. Stone, "Designing and implementing cross-sector collaborations: needed and challenging," Public Administration Review, vol. 75, no. 5, pp. 647-663, 2015.

[20] C. Ansell and A. Gash, "Collaborative governance in theory and practice," Journal of Public Administration Research and Theory, vol. 18, no. 4, pp. 543-571, 2008.

[21] Q. Hu, S. Khosa, and N. Kapucu, "The intellectual structure of empirical network research in public administration," Journal of Public Administration Research and Theory, vol. 26, no. 4, pp. 593-612, 2016.

[22] N. Kapucu, "Interorganizational coordination in dynamic context: networks in emergency response management," Connections, vol. 50, no. 2, pp. 139-146, 2005.

[23] Web of The Central People's Government of the People's Republic of China, "Act on addressing emergencies of Republic of China," August 2007, http://www.gov.cn/ziliao/ flfg/2007-08/30/content_732593.htm.

[24] K. G. Provan and P. Kenis, "Modes of network governance: structure, management, and effectiveness," Journal of Public Administration Research and Theory, vol. 18, no. 2, pp. 229252, 2007.

[25] S. E. Robinson, W. S. Eller, M. Gall, and B. J. Gerber, "The core and periphery of emergency management networks," Public Management Review, vol. 15, no. 3, pp. 344-362, 2013.

[26] H. Zhang, X. Zhang, L. Comfort, and M. Chen, "The emergence of an adaptive response network: the April 20, 2013 Lushan, China earthquake," Safety Science, vol. 90, pp. 14-23, 2016.

[27] D. F. Kettl, "Managing boundaries in American administration: the collaboration imperative," Public Administration Review, vol. 66, no. s1, pp. 10-19, 2006.

[28] C. J. Koliba, R. M. Mills, and A. Zia, "Accountability in governance networks: an assessment of public, private, and nonprofit emergency management practices following Hurricane Katrina," Public Administration Review, vol. 71, no. 2, pp. 210-220, 2011.

[29] Q. Hu, C. C. Knox, and N. Kapucu, "What have we learned since September 11, 2001? A network study of the Boston Marathon bombings response," Public Administration Review, vol. 74, no. 6, pp. 698-712, 2014.

[30] W. W. Powell, "Neither market nor hierarchy: network forms of organization," Research in Organizational Behavior, vol. 12, pp. 295-336, 1990.
[31] R. Yin, Case Study Research: Design and Methods, Sage Publication, 2013.

[32] Web of State Administration of work Safety, "Shandong Qingdao Sinopec east yellow "11.22" explosion leakage of oil pipeline especially big accident investigation report," January 2014, http://www.gov.cn/gzdt/2011-12/29/content_ 2032986.htm.

[33] W. Scott and K. Faust, Social Network Analysis: Methods and Applications, Cambridge University Press, Cambridge, UK, 1994.

[34] Netminerhttp://www.netminer.com/main/main-read.do.

[35] S. E. Robinson, W. Eller, M. Gall, and B. J. Gerber, “The core and periphery of emergency management networks: a multimodal assessment of two evacuation hosting networks from 2000-2009," SSRN Electronic Journal, vol. 15, pp. 1-38, 2012.

[36] S. O. Choi and R. S. Brower, "When practice matters more than government plans: a network analysis of local emergency management," Administration \& Society, vol. 37, no. 6, pp. 651-678, 2006.

[37] K. R. Isett, I. A. Mergel, K. Leroux, P. A. Mischen, and R. K. Rethemeyer, "Networks in public administration scholarship: understanding where we are and where we need to go," Journal of Public Administration Research and Theory, vol. 21, Supplement 1, pp. i157-i173, 2011.

[38] K. Chang, "Understanding cross-sector collaboration in emergency management: the dynamics of vertical and horizontal networks," Dissertations \& Theses-Gradworks, 2012. 


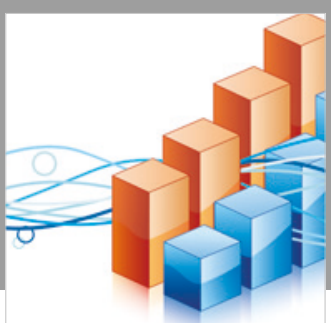

Advances in

Operations Research

\section{-n-m}
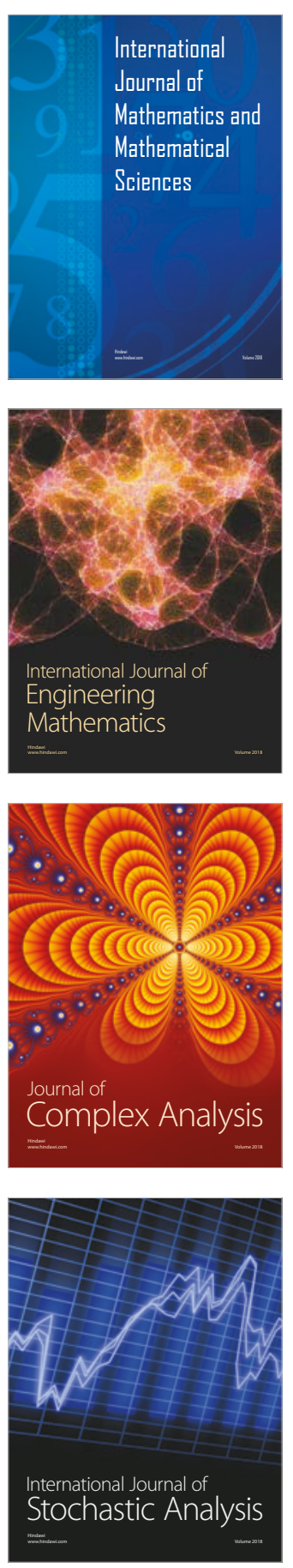
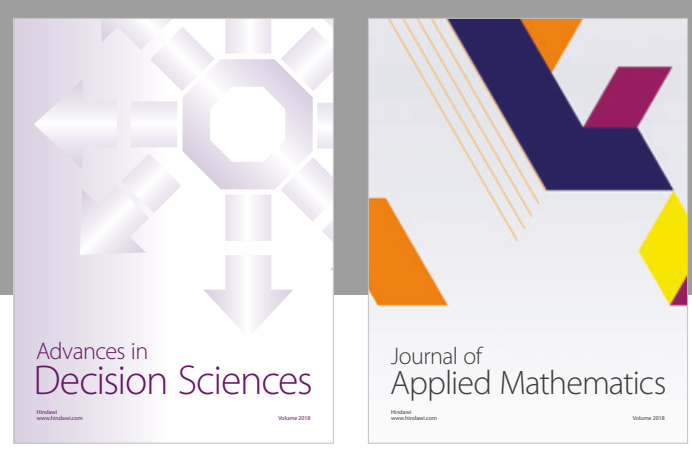

Journal of

Applied Mathematics
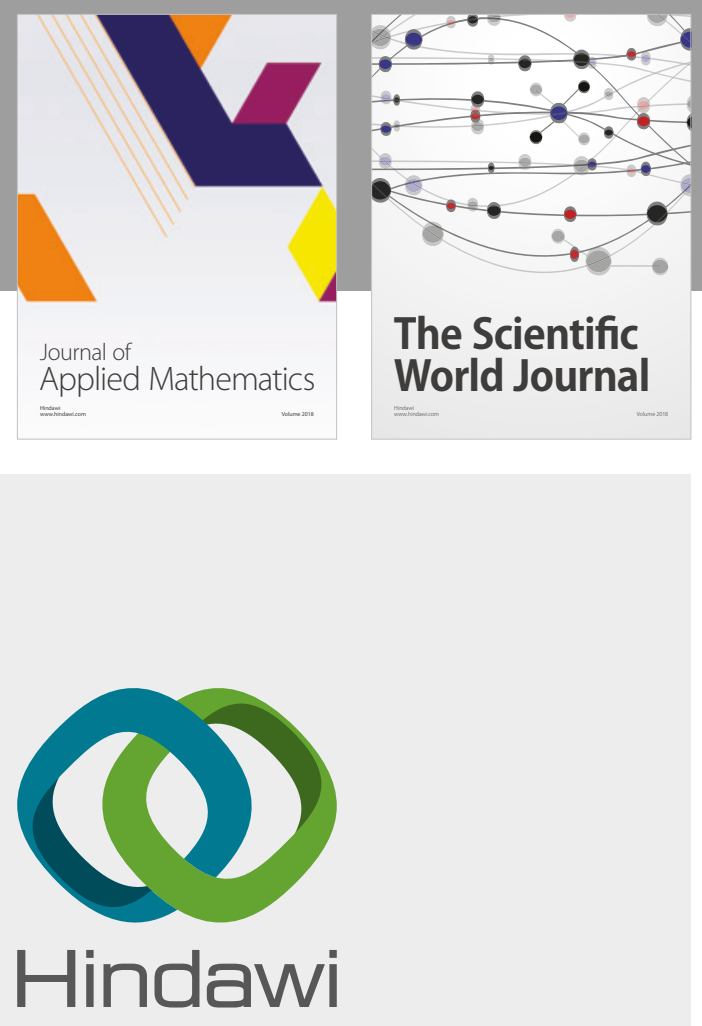

Submit your manuscripts at

www.hindawi.com

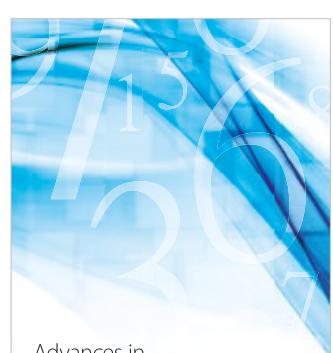

Advances in
Numerical Analysis
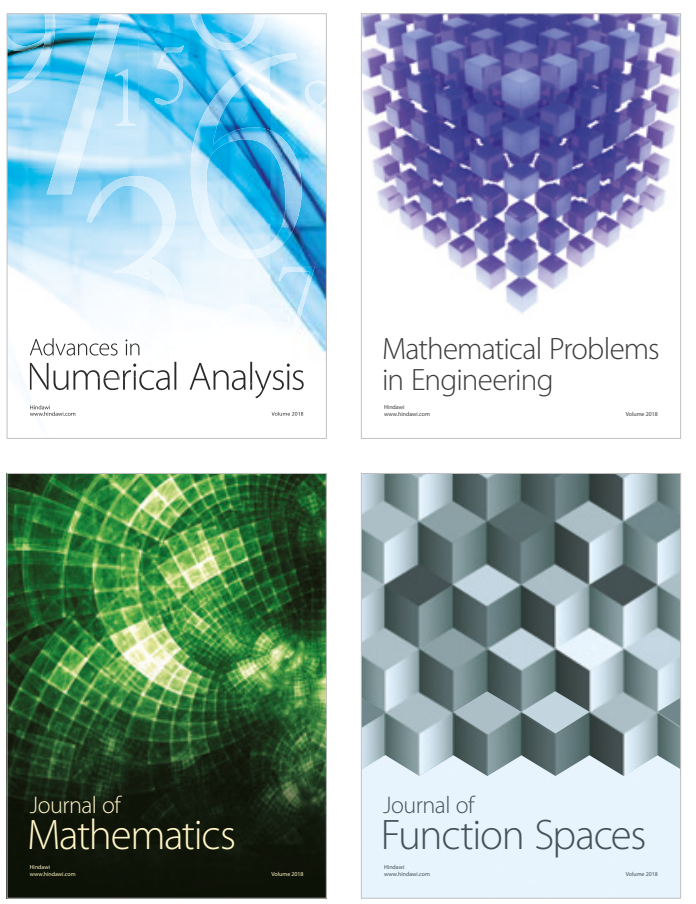

Mathematical Problems in Engineering

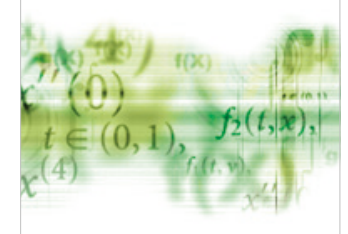

International Journal of

Differential Equations

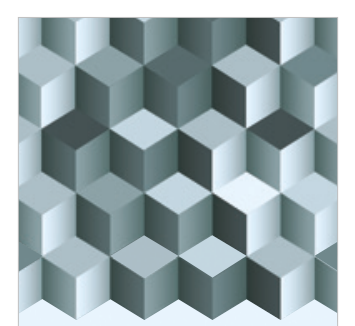

Journal of

Function Spaces
The Scientific

World Journal

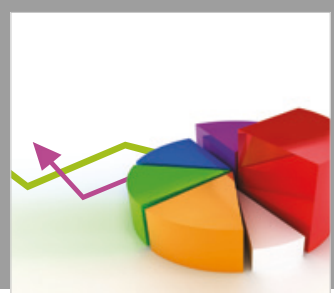

Journal of

Probability and Statistics
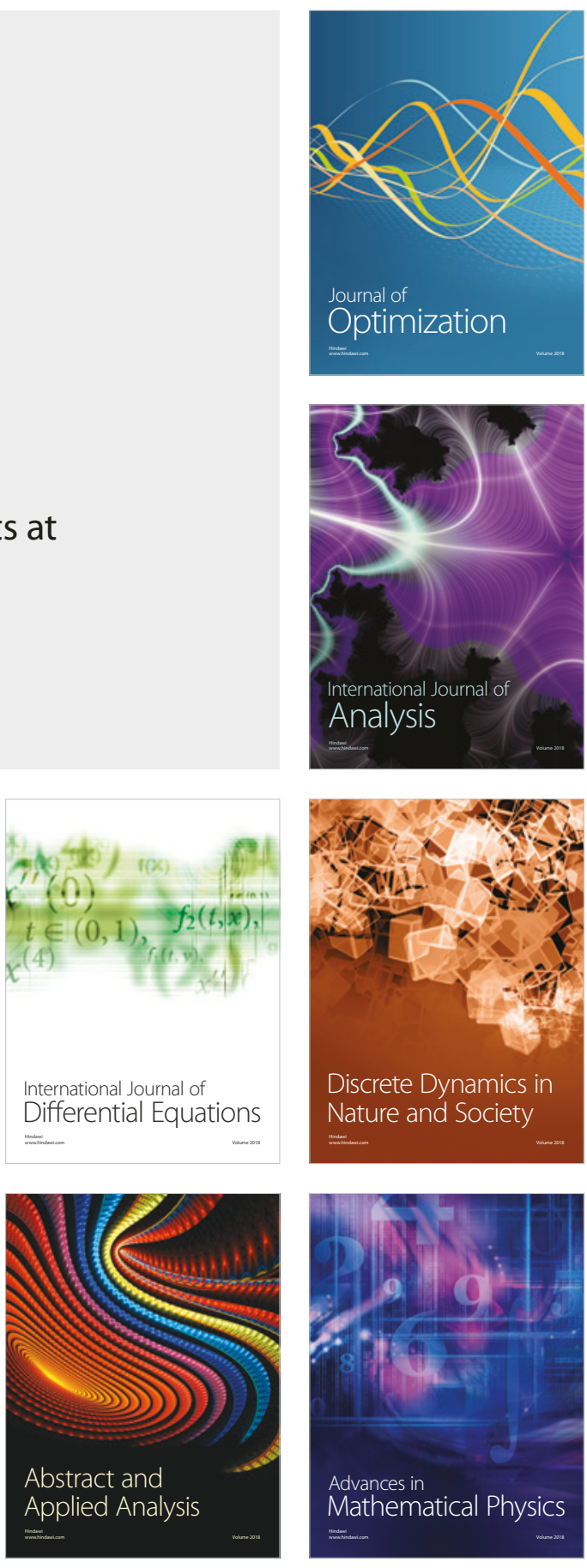